\title{
Conhecendo o funcionamento do labirinto
}

\author{
Aída R. M. de Assunção, ${ }^{1^{*}}$ Ciríaco Cristóvão T. Atherino ${ }^{2}$
}

\begin{abstract}
Resumo
O conhecimento das estruturas do labirinto é de fundamental importância para se entender a base das principais doenças que acometem o sistema vestibular e, consequentemente, introduzir a terapêutica adequada. A orelha interna é uma estrutura óssea oca, encravada no osso temporal e constituída de três porções distintas: a cóclea, responsável pela audição, o vestíbulo e os três canais semicirculares, responsáveis pelo equilíbrio em conjunto com a visão e o sistema proprioceptivo. No interior dessa estrutura óssea, encontramos estruturas membranosas. No vestíbulo, encontramos o sáculo e o utrículo e, nos canais semicirculares, os dutos semicirculares. Os canais semicirculares ocupam os três planos do espaço, permitindo que a estrutura membranosa, com suas células sensoriais, faça a identificação da aceleração angular, enquanto as estruturas membranosas do vestíbulo (as máculas sacular e utricular) permitem a regulação do equilíbrio estático e a percepção das acelerações lineares.
\end{abstract}

Descritores: Orelha interna; Vestíbulo do labirinto; Canais semicirculares.

\section{Abstract}

\section{Knowing the labyrinthine function}

The knowledge of the labyrinthine structure is of fundamental importance to be acquainted with the basis of the major diseases affecting the vestibular system and thus formulate the appropriate therapy. The Inner Ear is a bony structure, hollow, embedded in the temporal bone, and consists of three distinct parts: the cochlea, responsible for the hearing, the vestibule and the three semicircular canals responsible for the balance regulation together with the vision and the proprioceptive system. Within this bony structure there are membranous structures. In the osseous vestibule we found the saccule and the utricle and inside the semicircular canals, the semicircular ducts. The semicircular canals occupy the three planes of space allowing the membranous structures with its sensory cells make the identification of the angular accelerations, while the membranous structures of the vestibule (the saccular and utricular maculae) allow the static equilibrium adjustment and the perception of linear accelerations.

Keywords: Ear, inner; Vestibule, labyrinth; Semicircular canals.
1. Departamento de Especialidades Cirúrgicas. Faculdade de Ciências Médicas. Universidade do Estado do Rio de Janeiro. Rio de Janeiro, RJ, Brasil.

2. Disciplina de Otorrinolaringologia. Departamento de Especialidades Cirúrgicas. Faculdade de Ciências Médicas. Universidade do Estado do Rio de Janeiro. Rio de Janeiro, RJ, Brasil.

"Endereço para correspondência:

Secretaria da Otorrinolaringologia

Boulevard 28 de Setembro, 77, 50 andar

Rio de Janeiro, RJ, Brasil. CEP: 20551-030.

E-mail: otoneuro@uerj.br

Revista HUPE, Rio de Janeiro, 2015;14(1):28-30

doi:10.12957/rhupe.2015.14994

Recebido em 28/07/2014. Aprovado em 01/10/2014.

\section{Resumen}

\section{Conociendo el funcionamiento del laberinto}

El conocimiento de las estructuras del laberinto es de fundamental importancia para entender la base de las principales enfermedades que afectan al sistema vestibular $y$, por consiguiente, la introducción de la terapia adecuada. El oído interno es una estructura ósea hueca, enclavada en el hueso temporal y constituida por tres partes distintas: la cóclea responsable de la audición, el vestíbulo y los tres canales semicirculares encargados del equilibrio, junto con la visión y el sistema propioceptivo. Dentro de esa estructura ósea, encontramos estructuras membranosas. En el vestíbulo encontramos el sáculo y el utrículo y, en los canales semicirculares, los conductos semicirculares. Los canales semicirculares ocupan los tres planos del espacio permitiendo que la estructura membranosa, con sus células sensoriales, haga la identificación de la aceleración angular, mientras que las estructuras membranosas del vestíbulo (las máculas sacular y utricular) permiten la regulación del equilibrio estático y la percepción de las aceleraciones lineales.

Palabras clave: Oído interno; Vestíbulo del laberinto; Canales semicirculares. 


\section{Conhecendo o funcionamento do labirinto}

A orelha interna é um sistema complexo de espaços e estruturas no interior do osso temporal.Ela abriga dois sistemas sensoriais: a cóclea que contém os órgãos da audição, e o sistema vestibular, que comporta os órgãos responsáveis pelo equilíbrio. .,2,3 $^{1,3}$

O termo "labirinto ósseo" é usado para descrever a série de canais e cavidades no interior do osso temporal que contém os sistemas acima. Como se pode observar na figura 1, o labirinto ósseo consiste de uma câmara central chamada "vestíbulo", uma formação espiral, anterior, chamada "cóclea" e, posteriormente, três tubos em forma de arco denominados "canais semicirculares".

Este labirinto ósseo é preenchido por perilinfa-um ultrafiltrado do liquor semelhante ao líquido extracelular, ou seja, rico em sódio e pobre em potássio. No interior deste labirinto ósseo, cheio de perilinfa, existe uma série de tubos e bolsas membranosas, o labirinto membranoso. ${ }^{1,3}$ Este, por sua vez, é preenchido por um líquido de composição semelhante ao do líquido intracelular, ou seja, rico em potássio e pobre em sódio, a endolinfa (Figura 2).

A porção da orelha interna que envolve o equilíbrio é denominada "sistema vestibular" e corresponde ao vestíbulo ósseo e aos três canais semicirculares. A porção membranosa de cada sistema vestibular corresponde, portanto, ao utrículo e sáculo (no interior do vestíbulo ósseo) e aos três dutos semicirculares (no interior de cada um dos três canais semicirculares). Estas estruturas contêm cinco órgãos sensoriais: um em cada

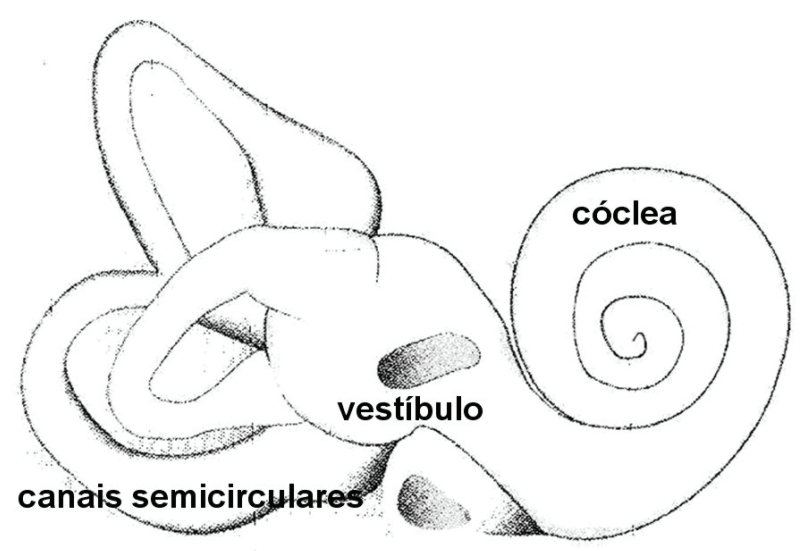

Figura 1. Labirinto ósseo e suas três porções. duto semicircular, um no utrículo e outro no sáculo., 1,2,3

As porções auditiva e equilibratória da orelha interna estão interconectadas. A perilinfa e a endolinfa são comuns a ambos os sistemas. Portanto, distúrbios que afetam a orelha interna podem afetar ambos os sistemas sensoriais, ou seja, podem produzir tanto problemas do equilíbrio quanto perdas auditivas. Um pequeno conduto, o duto reuniens, conecta o duto coclear (também chamado "rampa média") com o sáculo, que, por sua vez, se conecta ao utrículo.

O utrículo e o sáculo são porções do labirinto membranoso que percebem a nossa movimentação linear (isto é, dirigindo um automóvel, dentro do elevador). Dentro deles, encontramos estruturas sensoriais: as máculas utricular e sacular, que respondem à gravidade $\mathrm{e}$ a acelerações lineares. Estas máculas são compostas de um epitélio sensorial com células ciliadas de dois tipos (I e II). Sobre elas, existe uma membrana gelatinosa com inúmeros cristais de carbonato de cálcio, os otólitos (ou otoconias), membrana esta denominada "membrana otolítica" (Figura 3).,2,3

Essas células ciliadas possuem, na sua superfície, vários estereocílios e um cinetocílio, que nos dá a orientação de estimulação da célula (Figura 4), ou seja, correntes endolinfáticas na direção do cinetocílio desencadeiam excitação da célula, enquanto que correntes contra o cinetocílio provocam inibição celular.

Voltando à figura 3, pode-se observar que, como a orientação celular varia muito em cada mácula, o deslizamento da membrana otolítica em uma determinada direção provoca, ao mesmo tempo, excitação em vários grupos celulares e inibição em outros. Estas combinações fornecem ao sistema nervoso central

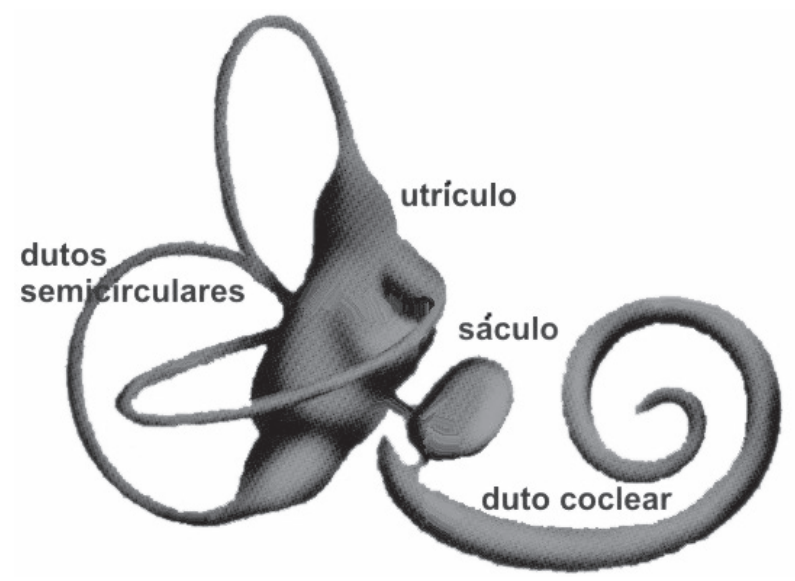

Figura 2. Labirinto membranoso: estas estruturas estão no interior do labirinto ósseo e estão envolvidas por perilinfa. No seu interior, circula outro líquido, a endolinfa. 


\section{Artigo de revisão}

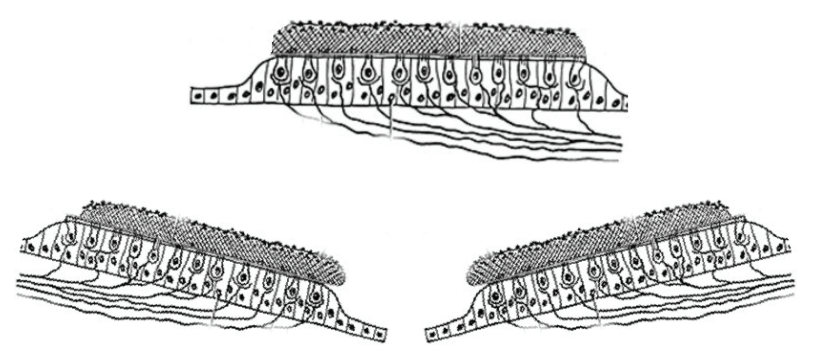

Figura 3. Esquema das máculas utricular e sacular: a movimentação da cabeça faz deslizar a membrana otolítica, cheia de otólitos (ou otoconias), cristais de carbonato de cálcio, e esta estimula ou inibe as células ciliadas tipos I e II subjacentes.

o posicionamento correto de nosso corpo no espaço.

Os dutos semicirculares contêm os órgãos sensoriais que detectam rotação, como a cabeça girando sobre o pescoço. Os três dutos semicirculares se abrem no utrículo (Figura 2) e ocupam os três planos do espaço (Figura 5).

Cada duto semicircular tem uma extremidade alargada denominada "ampola", onde está situado o órgão sensorial do duto semicircular - a crista ampular. Esta contém um epitélio sensorial ciliado encimado por uma cúpula gelatinosa que tem o mesmo peso específico da endolinfa. Portanto, fica flutuando na mesma, embora tenha um pequena inserção no teto da ampola. Isto significa que ela pode se mover quando o fluido se move, mas com limitações. ${ }^{1,2,3}$

Os dutos semicirculares estão arranjados de forma a detectar um movimento em qualquer direção. As células ciliadas das cristas ampulares também são de dois tipos (I e II). Ambas têm vários estereocílios e um cinetocílio que nos dá a direção da sua estimulação. Este cinetocílio das células das cristas ampulares são maiores que os das células das máculas. Mas, da mesma forma, correntes em direção ao cinetocílio são estimulantes, enquanto as correntes que fogem do cinetocílio são inibitórias. No duto lateral (ou horizontal), os cinetocílios estão localizados na direção do utrículo. Contudo, nos dutos anterior (ou superior) e posterior,

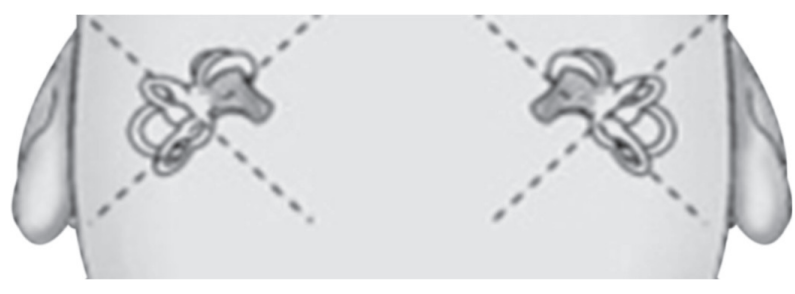

Figura 5. Canais semicirculares de ambos os lados ocupando os três planos do espaço.
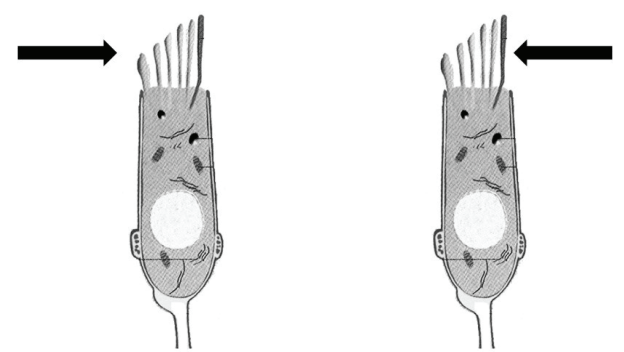

Figura 4. À esquerda, corrente endolinfática em direção ao cinetocílio, excitação celular. À direita, corrente endolinfática contra o cinetocílio, inibição celular. $\mathbf{O}$ cinetocílio é o mais alto e de cor mais escura.

os cinetocílios estão situados na porção celular mais afastada do utrículo. Na prática, isto significa que o duto lateral é estimulado por correntes endolinfáticas que vão em direção à ampola e é inibido por correntes que fogem dela. Já nos dutos anterior e posterior, ocorre o contrário: a corrente que foge da ampola é a excitatória, enquanto a que vai de encontro à ampola é inibitória. ${ }^{1}$

Pautado nesta orientação celular diferente nas diversas cristas ampulares e na movimentação da endolinfa, um cientista alemão chamado Ernst Julius Richard Ewald (1855-1921) elaborou três leis que são, até hoje, a base dos estudos labirínticos: ${ }^{4}$

- $1^{a}$ Lei: um estímulo de um duto semicircular provoca um movimento ocular no plano do duto estimulado.

- $2^{\mathrm{a}}$ Lei: no duto semicircular horizontal (lateral), o movimento ampulípeto (em direção à ampola) provoca maior estímulo que o ampulífugo (direção contrária à ampola).

- $3^{\mathrm{a}}$ Lei: nos dutos verticais (superior e posterior), o reverso é verdadeiro.

Em resumo, as máculas utricular e sacular respondem às acelerações lineares, enquanto as cristas ampulares respondem às acelerações angulares. ${ }^{1,2}$

\section{Referências}

1. Hamill TA, Price LL. The Hearing Sciences, 2nd edition, San Diego: Plural Publishing Inc.; 2014. 493p.

2. Teixido M, Isildak H. Anatomy and Embriology of the Vestibular Apparatus. In O'Reilly RC, Morlet T, Cushing SL. Manual of Pediatric Balance Disorders, San Diego, Plural Publishing Inc.; 2014. 194p.

3. Netter F. Interactive Atlas of Clinical Anatomy. DxR Development Group Inc.; 1997 (CD).

4. Hungria H. Otorrinolaringologia, 7a edição, Rio de Janeiro: Editora Guanabara Koogan S.A.; 1995. 489p. 